\title{
CurríCulo e teCNOLOGIA: RECONFIGURANDO PRÁTICAS CULTURAIS ATRAVÉS DO KATYBOOK*
}

\author{
Roberta Sales Lacê Rosário \\ Universidade do Estado do Rio de Janeiro, Rio de Janeiro, \\ Rio de Janeiro, Brasil \\ BONNIE AXER \\ Universidade do Estado do Rio de Janeiro, Rio de Janeiro, \\ Rio de Janeiro, Brasil
}

\begin{abstract}
RESUMO: Este artigo nos instiga e nos aproxima, na condição de pesquisadoras do campo do currículo, para problematizar as possibilidades de (re)configuração dos processos de produção curricular como práticas que se desenvolvem a partir das produções culturais na/com a tecnologia. Além disso, propõe discutirmos as relações e produções culturais dos sujeitos que permeiam o espaço da escola enquanto produções que reescrevem novas/ outras práticas constituidoras do currículo e da cultura. Assim, propomos nossas análises a partir do episódio de criação de um chat (bate-papo) nomeado de katybook pelos estudantes do $5^{\circ}$ ano do EF do CAp/UERJ. Acreditamos que discutir o currículo nesse contexto nos faz ir além das proposições dos documentos curriculares, faz-nos analisá-lo como um espaço constituído por posturas, atitudes e falas.
\end{abstract}

Palavras-chave: Currículo. Tecnologia. Cultura. Prática/política.

A contemporaneidade requer culturas que se misturam e ressoam mutuamente. Que convivem e se modificam. E se modificam modificando outras culturas pela convivência ressonante. Um processo contínuo, que não para nunca porque não se limita a um receber ou dar. É contaminação. É ressonância. Estabelece-se uma troca permanente, constante e sem hegemonias predeterminadas e preestabelecidas, definidas a priori, de fora e sem a presença dos implicados, de todos os implicados, estando integrados no processo, num comportamento caótico, com momentos de diferentes graus de ressonância. (PRETTO, 2006, p. 125)

\footnotetext{
* Artigo recebido em 7/3/2014 e aprovado em 5/5/2014.
} 
Este artigo propõe discutirmos as relações e produções culturais dos sujeitos que permeiam o espaço da escola enquanto produções que constituem e modificam as práticas curriculares. Assim, trazemos enquanto questionamento central a tecnologia como linguagem que constitui e relaciona os sujeitos em diferentes espaços e tempos. Uma linguagem que está para além de artefato midiático e/ou equipamento tecnológico, mas que reescreve novas/outras práticas constituidoras do currículo e da cultura. Dessa forma, traremos como pontos de articulação currículo - cultura - tecnologia - prática/política para pensarmos as práticas cotidianas reconfiguradas nas relações dos sujeitos com o seu outro e com a linguagem da tecnologia enquanto produções culturais do currículo.

Assim, o que nos instiga e nos aproxima como pesquisadoras do campo do currículo, no presente estudo, são possibilidades de (re)configuração dos processos de produção curricular enquanto práticas que se desenvolvem a partir das produções culturais na/com a tecnologia. Para tanto, propomos nossas análises a partir do episódio de criação de um chat (bate-papo) nomeado de katybook pelos estudantes do $5^{\circ}$ ano do ensino fundamental do Colégio de Aplicação Fernando Rodrigues da Silveira - CAp/ UERJ. No bate-papo em questão, o canal de comunicação era o quadro branco da sala de aula e o nome dado por eles foi uma homenagem a uma cantora americana que fazia aniversário durante a semana do fato ocorrido.'

Optamos por trazer tal situação porque acreditamos que ela anuncia reconfigurações de ações/práticas em outros espaços e tempos dentro/fora da escola, que não se limitam ao espaço físico, mas, em vez disso, mostram que o transcendem de diferentes maneiras. Dessa forma, pensar o currículo nesse contexto nos faz ir além da observação e análise dos documentos curriculares e de seus possíveis determinismos, mas percebê-lo como um espaço constituído por posturas, atitudes e falas, numa cadeia discursiva de ação política, que permite sua construção e reconstrução contínua, no movimento das produções culturais cotidianas.

\section{KATYBOOK: PROBLEMATIZANDO AS PRÁTICAS CULTURAIS EM SALA DE AULA}

Nesta seção, trazemos trechos do registro do diário de campo, citado anteriormente, para iniciarmos as nossas discussões sobre as produções cotidianas que (re)significam as práticas curriculares. São práticas que não são determinadas e ou aprisionadas por planejamentos e ou planos de aula rígidos.

Sendo assim, acreditamos que todo planejamento curricular é arbitrário, falho em si mesmo, visto que é produzido em meio a inúmeras 
relações de poder, e essa incompletude própria de todo planejamento e de todo currículo é o que possibilita o desplanejamento. "Desplanejar não significa agir sem planejar, mas agir segundo um planejamento que, no mesmo ato, é desmontado" (LOPES; MACEDO, 2011, p. 69). Ainda que se tenha a intenção de controle, não é possível prever e catalogar as ressignificações e as recontextualizações feitas nas vivências curriculares.

Dessa forma, acreditamos que os registros que fazemos durante as práticas cotidianas dentro/fora da sala de aula nos dão pistas de que, muito além de comportamentos e/ou posturas esperadas, acontecem ações e criações que revelam autoria dos sujeitos que não se limitam a predeterminações, ao contrário disso: disputam sentidos e significados, em posições ambivalentes de poder, para as suas práticas culturais.

Assim, nossas análises partem do diálogo entre as crianças do $5^{\circ}$ ano do ensino fundamental em atividade em sala de aula. $O$ diálogo começa em um elogio ao colega, enquanto brincavam ainda na ausência da professora. Então, surge no canto do quadro branco a frase:"O Heitor ${ }^{2}$ é o melhor professor do mundo e da atmosfera". Logo abaixo, vieram uma sucessão de comentários que não foram necessariamente sobre a brincadeira de dar aula, mas sobre as crianças que aproveitaram o momento e o espaço interativo para escrever também. Com isso, surge abaixo:"Cemira está namorando...,' mas o nome não deu para ler porque fora apagado muito rapidamente, seguido da palavra "mentira", escrita pela aluna mencionada. Nesse momento, o fato de apagar a mensagem escrita pela colega e, em seguida, a resposta abaixo fez o colega Heitor interpelar, dizendo:

[...] Não pode apagar porque no facebook não pode apagar assim, a mensagem fica lá", mas logo foi interrompido por duas meninas dizendo que podia apagar sim! (Trecho retirado do diário de campo da pesquisa de Mestrado, novembro de 2012).

O registro nos possibilita analisar uma produção de escrita interativa dos estudantes durante a aula, incitada pelo diálogo e pela reconfiguração dos meios de comunicação, mais especificamente os processos de comunicação eletrônicos e redes sociais, que não são os mesmos diálogos realizados por eles em tais redes, mas ressignificados por elas.

Em diálogo com os estudos de Appadurai (2004) sobre os processos de mudança na comunicação de massas, possibilitando a criação de novos "eus imaginados", de mundos imaginários, observamos a produção dos estudantes como um momento de deslocamento entre os espaços - nesse caso, os espaços virtuais e o da sala de aula. Esse trânsito possibilita outras organizações de pensamento, sentimentos, o que reconfigura suas percepções 
de mundo e modifica suas ações. $O$ autor nos possibilita perceber a criação de mundos imaginários e principalmente a imaginação como principal característica constituinte da subjetividade moderna dos sujeitos, diante das rupturas a que se refere como ruptura geral nas relações intersocietais. Assim, [...] imaginação como propriedade de coletivos e não apenas como faculdade do indivíduo dotado (p. 20). Dessa forma, podemos compreender a imaginação como componente chave da nova ordem global (p. 47).

Com essa perspectiva, problematizamos como os estudantes trazem para o espaço da sala de aula algo que constitui seus mundos imaginários e que eles partilham no trânsito entre os mundos real e virtual ou simplesmente um mundo virtualizado. Tal produção reproduz uma interatividade que está além dos espaços virtuais, mas que se reconfigura como produção híbrida, tal como Appadurai (2004, p. 22) afirma: "uma prática cultural de todos os dias através da qual se transforma a obra da imaginação".

Dessa forma, podemos analisar as redes de conhecimento e diálogos tecidos dentro/fora da escola e ou da sala de aula, como no episódio do katybook, para além das redes tecnológicas, serem possíveis por conta de uma globalização de fronteiras fluidas, movediças, ressignificadas não só pelas relações das crianças e adolescentes conectados à rede da internet, mas também contribuindo para dar outros significados às relações em outros espaços e tempos que estão além da conexão por meio da rede da internet, o que Appadurai (2004) nos propõe pensar a respeito dos processos culturais globais.

Nesse sentido, a cultura é, em nossa percepção, campo de conflitos e disputas, um território amplo e diverso que precisa ser entendido como tal. Operar nessa lógica performática da cultura é operar num tempo de repetição e reprodução onde circulam sentidos ambivalentes. Portanto, a cultura é um espaço de criação, e o currículo é a própria criação de sentidos que acontece num espaço indecidível (DERRIDA, 2001). É um espaço liminar, situado em meio às designações de identidade, uma ligação que constrói a diferença, ou melhor, um movimento que evita que a diferença seja vista através de polaridades e binarismos fixos, pois tal espaço reconhece as diferenças e as encara.

Com o episódio do katybook, trazemos à tona a possibilidade de releitura do currículo e do planejamento curricular, constituído por práticas de significação, a partir das contribuições pós-estruturalistas, compreendendo-o como linguagem, vivência e experimentação. Trata-se de um discurso que constrói a realidade e não apenas nomeia o que existe (LOPES \& MACEDO, 2011). 
CuRRíCulo: um ENTRE-LUGAR DE ENUNCIAÇÃO CULTURAL

Iniciamos esta discussão ressaltando que interpretar o currículo como enunciação cultural significa dizer que interpretamos e percebemos o currículo como produção contínua de sentidos, uma produção de sentidos não esperada, mas sim uma produção em movimento que envolve todos os sujeitos e diferentes instâncias em tal processo. Tal perspectiva não quer dizer que não há mais normatizações curriculares com a intenção de controle; elas existem, visto que há sempre a tentativa de controle de significação constituinte da política. No entanto, essa abordagem nos permite reconhecer a ambivalência existente nessas relações, assumindo os limites e impossibilidades de essas tentativas controladoras se darem por completo.

Trata-se de pensar os tantos sentidos negociados nos contextos específicos e diferenciados da produção curricular, com decisões abertas, flexíveis e provisórias que impossibilitam um fechamento total, onde não se pode prever a relação entre existência dessas decisões e ações que lhe serão conferidas. As posições que são tomadas seguem esclarecidas de sua provisoriedade - ou seja, são práticas articulatórias onde as posições e as identidades, ao serem significadas, fixam-se - ao mesmo tempo em que deslocam sentidos, uma vez que essas fixações são sempre parciais.

Ao considerarmos os movimentos, articulações e posicionamentos dos diferentes sujeitos, problematizamos a produção de políticas de currículo enquanto construção mutável e indeterminada. Assim, pensamos o currículo enquanto arena de diferentes sentidos que lutam por legitimidade, como nos sugerem Lopes e Macedo (2011), possibilitando aos sujeitos a construção de identidade nas fissuras, como aponta Bhabha (2010), dialogando com a diferença e produzindo "cadeias de subjetividade".

Essas fissuras, segundo Bhabha (2010), constituem o processo de dominação e o discurso curricular que repete sem repetir, ou melhor, que é performático em suas repetições, visto que o sujeito do enunciado é diferente do sujeito da enunciação, uma vez que seus tempos são diferentes. Nesse sentido, não é possível ignorar a existência de lacunas no próprio ato de significação, o que impede que qualquer fechamento pretendido seja plenamente alcançado, uma vez que toda tentativa de controle traz, em si, lacunas que marcam a incompletude dos sujeitos e a ambivalência da própria linguagem. Sendo assim, há ambivalências no processo de produção e vivência curricular.

Para além de operar com a ideia de existência desses mecanismos de controle, o que nos chama a atenção ainda é a existência de estratégias de negociação, resistência e modificação para com esses mecanismos e que, 
ao serem reconhecidos, são burlados, modificados, discutidos, disputados e traduzidos. A criação de um bate-papo on-line vivenciado sem o uso da internet, em um quadro onde as escritas escapam aos conteúdos, nos instiga a questionar a produção curricular regulada e nos obriga a lidar com suas ambivalências constituintes da produção política e curricular.

É ainda Bhabha (2010) quem nos chama a atenção para o reconhecimento de temporalidades distintas que se dão no terceiro espaço, ou entre-lugar, que, neste trabalho, entendemos ser o espaço-tempo em que a produção curricular acontece. Segundo o autor, trata-se do próprio local da cultura, um local de negociação, contato e interação entre culturas e indivíduos. É o terreno para a elaboração de estratégias de subjetivação - singular ou coletiva - que dá início a novos signos de identidade e postos inovadores de colaboração e contestação, no ato de definir a própria ideia de sociedade e, neste estudo, de currículo.

Não é possível ignorar a existência de lacunas no próprio ato de significação, o que impede que qualquer fechamento pretendido seja plenamente alcançado, pois toda tentativa de controle traz em si as lacunas que marcam a incompletude dos sujeitos e a ambivalência da própria linguagem. Reconhecer que o tempo da produção é diferente do tempo da vivência curricular não significa que estamos falando de propostas distintas e, do ponto de vista que operamos, ambos são facetas do mesmo processo de produção política. Sendo assim, interpretar o currículo como enunciação permite reconhecer a ambivalência existente nas relações políticas, assumindo os limites e impossibilidades de essas tentativas controladoras se darem por completo.

Com esse entendimento, argumentamos ser o currículo o entre-lugar da escola, o que nos permite perceber o espaço da sala de aula enquanto espaço de produção de política curricular e não apenas espaço de implementação de políticas curriculares externas ao contexto da escola. Nesse sentido, entendemos serem possíveis tempos diferentes de produção e vivência, o que não significa pensarmos em contextos isolados de produção curricular.

Desenvolver neste trabalho a perspectiva de produção da política de currículo como prática articulatória (BARREIROS e FRANGELLA, 2010) possibilita trazer ao debate a construção da identidade sendo ela mesma uma prática política, um campo instável e de transição. Dessa forma, os processos que envolvem o sujeito, que se apresenta aqui como sujeito da falta e que age na indecidibilidade, como aponta Burity (2010), tem a constituição da sua identidade como algo em constante processo de desenvolvimento, por meio de movimentos de prática política cotidiana. 
Com isso, entendemos ser a cultura a possibilidade de movimentos de criação, e o currículo como o espaço onde essas criações enunciam sentidos, num espaço indecidível e intersticial onde as culturas convivem e negociam a sua existência (DERRIDA, 2001) - um espaço liminar, situado em meio às designações de identidade, uma ligação que constrói a diferença, ou melhor, um movimento que evita que a diferença seja vista através de polaridades e binarismos fixos, pois tal espaço reconhece as diferenças e as encara. Falar, portanto, de um currículo entendido como entre-lugar é falar de uma produção que se dá "nos excedentes da soma das 'partes' da diferença" (BHABHA, 2010, p. 16). Uma soma equivalente que não apaga as diferenças, mas as coloca em diálogo.

Como toda enunciação, o currículo reitera traços de sentidos supostamente partilhados, como'estratégia de representação da autoridade' (p. 65), sem que seus sentidos sejam transparentes ou miméticos. É híbrido porque obrigado a negociar, de forma agonística e incompleta, seus sentidos com o outro. Hibridiza objetos impossíveis que criamos por intermédio de uma pretensa diferenciação. Conhecimentos acumulados, culturas vividas, expectativas de futuro - todos eles também híbridos em sua própria constituição - são nomeados como entidades controláveis. (MACEDO, 2010, p. 11, citando BHABHA, 2003)

O entre-lugar curricular que trouxemos anteriormente é esse indecidível no qual operamos a partir da performatividade, pois, mesmo que seja impossível decidir nele, ainda sim se faz necessário. Esse terceiro espaço produz sentido no diálogo entre lugares distintos (sujeitos, culturas e diferenças que enunciam), zona de descentramento que vêm testemunhar, ao mesmo tempo, o diferimento (repetição) e a diferença. Com essa perspectiva, defendemos um currículo não somente como prática ou simplesmente documento escrito, mas, fundamentalmente, como espaço de criação de sentidos, pois assim é possível perceber a existência de relações interculturais e de um poder oblíquo (CANCLINI, 2008), contingente e constituinte desse processo.

\section{CULTURAS: PROBLEMATIZANDO AS EXPERIÊNCIAS EM SALA DE AULA}

Sendo, então, o currículo um espaço indecidível, as suas negociações se dão através de fluxos de discursos (globais e locais), de perspectivas, de posições, de poder, de identidades, de diferenças, de políticas, de conhecimento e cotidianos. Um fluxo de sentidos que não se completa, mas que está sempre borbulhando de sentidos provisórios e incompletos que se (re)criam, a partir das relações dos sujeitos envolvidos, de suas culturas, 
suas demandas e interesses que validam posturas e são negociados a todo instante na produção curricular.

Ao descrever e pensar o currículo dessa forma, não compartilhamos de determinada visão de cultura defendida pela Antropologia, que a compreende como um bloco fechado de partilhamentos históricos transmitidos por gerações em nome de uma tradição. De maneira outra, pensamos a cultura enquanto o próprio lugar de enunciação, um espaço de criação que está para além de repertórios de saberes e significados partilhados historicamente. A cultura é, a nosso ver, um campo de conflitos e disputas, um território amplo e diverso que precisa ser entendido como tal. Deixamos de pensar nela somente como referência do passado para pensarmos nela a partir de uma perspectiva performática (BHABHA, 2010).

Ainda segundo o autor, a cultura é um espaço de enunciação de identidades, em que a diferença aparece, pois se trata de um processo constante de transformação. Produzir cultura é falar, viver e não somente reescrever o que já está posto. Esse entendimento interativo percebe a cultura como algo que é a todo o tempo (re)composto a partir de uma ampla variedade de fontes resultantes de um processo híbrido e fluido. Nesse sentido, discursos globais e locais negociam a sua existência, políticas nacionais e locais dialogam, disputam e decidem suas entradas na escola. Operamos, então, a partir de culturas plurais que se misturam e, ao se misturarem, criam outros pertencimentos culturais - "um movimento incessante de produção de sentidos que se utiliza de fragmentos de sentidos deslocando-os sempre no tempo e no espaço" (MACEDO, 2010, p. 20).

Entendendo que"os sentidos são construídos pela linguagem, pelos sistemas de significação que nada mais são do que a própria cultura" (LOPES \& MACEDO, 2011, p. 203), começamos a problematizar como sujeitos constituem a produção curricular em meio a práticas de significação e assim, "o currículo é, como muitas outras, uma prática de atribuir significados, um discurso que constrói sentidos. Ele é portanto, uma prática cultural" (idem, p. 203).

Dessa forma, a nossa proposta em analisar um episódio em sala de aula, como neste caso com o episódio do katybook, incita problematizarmos questões que estão em diálogo com os processos curriculares, não localizados no espaço da sala de aula, mas muito propriamente no trânsito pelos espaços e tempos, o que modifica leituras, ações, criações, pensamentos e interpretações.

Podemos ainda destacar que as práticas e ações de autoria, principalmente as (re)criadas no/com o coletivo, têm posto como desafio para pensarmos tais articulações dos sujeitos enquanto ressignificação contínua dos processos de produção cultural. Não se trata de apenas um episódio em 
si, esvaziando todas as suas outras possíveis organizações e atravessamentos, mas o que podemos questionar e analisar são os desdobramentos que se dão a partir dele, ou mesmo tecidos junto a ele, mas que ainda requerem perspicácia em nossas análises, considerando as inter-relações entre o espaço e o tempo.

A partir dessas perspectivas, pensamos a experiência da/na escola sendo esta um espaço de articulação, de enunciação de diferentes culturas, onde precisa ser permitida e valorizada a inter-relação e a intertextualidade entre as culturas que se processam no interior de um sistema baseado numa relação de poderes (TURA, 2002). É assim que se configuram as vivências em sala de aula, sejam quais forem.

Tal circularidade permite aproximações e deslocamentos de contextos culturais diferenciados que se ampliam em um diálogo que não só provoca aproximações mas também inúmeras descontinuidades. 0 currículo, assim, é entendido como um espaço intervalar que, ainda que projete identidades, estas jamais poderão ser congeladas, visto que não há representação em si, mas, sim, momentos de identificação incessantes. No entanto, essa compreensão não implica negar que a escola e seus espaços têm se constituído como espaços regulados e normativos, posto que, por vezes, são orientados por perspectivas padronizadas e homogeneizantes.

Podemos dizer, então, que o entre-lugar é um espaço de ressignificação, de (re)criação, tempo (re)visionário, um retorno ao próprio presente para reescrevê-lo, um espaço de intervenção no aqui e no agora. Ou seja, um espaço-tempo contingente em que há relação e negociação entre as culturas existentes e suas diferenças. É nesses espaços-tempos de fronteira que diferentes perspectivas e discursos se hibridizam, relacionam-se e dialogam.

Estamos falando de um fluxo em contínuo movimento, movimento em si, um movimento impensável, atemporal, imaterial, assincrônico, indecidível. Mas como, então, pensar a reconfiguração das nossas práticas em meio a esse fluxo de adiamentos constantes de sentido? Talvez pensar a prática curricular pelo viés cultural, no qual as relações de poder não deixam de existir, as fissuras constituintes da relação política precisam ser evidenciadas, desconstruídas e repensadas, em que as relações sociais e curriculares se dão em meio a enunciações e se tornem aqui, um caminho a percorrer.

\section{CONSIDERAÇÕES FINAIS}

Com as leituras de alguns autores pós-estruturalistas, como Lopes e Macedo, Burity e também autores dos estudos culturais como Bhabha, Canclini e Appadurai, defendemos o currículo, a cultura e as tecnologias 
como linguagem, pois os entendemos enquanto práticas de significação, em que é possível (re)constituir e dar novos/outros sentidos para as práticas cotidianas. Nesse sentido, o episódio do katybook criado pelos estudantes do $5^{\circ}$ ano do ensino fundamental permite-nos pensar que as vivências na escola jamais poderão ser congeladas, haja vista que reconhecemos que não há representação em si, mas sim momentos de identificação incessantes. Podemos dizer, então, que o currículo como entre-lugar é um espaço de (re) significação, de (re)criação, de tempo revisionário, um retorno ao próprio presente para reescrevê-lo, um espaço de intervenção no aqui e no agora (BHABHA, 2010). Tal intervenção questiona as divisões binárias, posto que estamos operando em bases híbridas.

Sendo assim, pensamos as experiências escolares enquanto fronteiras, onde não há um pertencimento cultural original, mas um lugar onde algo começa a se fazer presente. Essa fronteira traz um encontro com o novo, renova o próprio presente constantemente. Ou seja, um espaço-tempo contingente onde há relação de negociação entre as culturas existentes e suas diferenças. É, então, nesses espaços-tempos de fronteira que diferentes perspectivas e discursos se hibridizam, relacionam-se e dialogam. Além disso, pudemos problematizar a autoria e a criação de outros possíveis mundos imaginários, "eus imaginados", o que nos propõe analisarmos os deslocamentos entre os espaços, ultrapassando e/ou desmanchando fronteiras e/ou barreiras de espaço e tempo.

CURRICULUM AND TECHNOLOGY: RESETTING CULTURAL PRACTICES THROUGH KATYBOOK

ABSTRACT: This article challenges us and brings us together as researchers in the field of curriculum to discuss possibilities for the (re) configuration of the processes of curriculum production, as practices undertaken using cultural productions in/with technology as a basis. The study also discusses the relations and cultural productions of the subjects who frequent the school milieu as productions which rewrite new/ other practices which construct curriculum and culture. With this in mind, our analyses stemming from the setting up of a chat named katybook by $5^{\text {th }}$ year students in Colégio Aplicação, at the Universidade do Estado do Rio de Janeiro are presented. We believe that discussing the curriculum in this context forces us to go beyond the proposals of curriculum documents, and analyze it as a space made up of stances, attitudes and discourse.

KEY WORDS: Curriculum. Technology. Culture. Practice and policy. 


\section{CURRÍCULOYTECNOLOGÍA: RECONFIGURANDO PRÁCTICAS CULTURALES A TRAVÉS DEL KATYBOOK}

RESUMEN: Este artículo nos instiga y nos acerca, como investigadoras del campo del currículo, a problematizar las posibilidades de (re) configuración de los procesos de producción curricular, como prácticas que se desarrollan a partir de las producciones culturales en/con la tecnología. Además de eso, propone discutir las relaciones y producciones culturales de los individuos que permean el espacio de la escuela como producciones que reescriben nuevas/otras prácticas constituidoras del currículo y de la cultura. Por lo tanto, proponemos nuevos análisis partiendo del episodio de la creación de un chat (charla) llamado katybook por los estudiantes del quinto grado de primaria del CAp/UERJ (Colegio Aplicación de la Universidad Estatal de Río de Janeiro). Creemos que discutir el currículo en este contexto nos hace ir más allá de las proposiciones de los documentos curriculares y analizarlo como un espacio constituido por posiciones, actitudes y discursos.

Palabras claves: Currículo. Tecnología. Cultura. Práctica y política.

\section{NOTAS}

1. O registro foi feito na sala de aula durante uma atividade de matemática com a turma e a professora, relatado no diário de campo, no período das observações nas diferentes turmas do $5^{\circ}$ ano do ensino fundamental, durante pesquisa de Mestrado de uma das autoras deste artigo.

2. Os nomes dos alunos, assim como o nome de todos os sujeitos da pesquisa, são fictícios, para preservar a identidade pessoal, mesmo tendo, no momento da pesquisa mencionada anteriormente, a autorização de todos/as adultos e responsáveis pelas crianças através de termos assinados.

\section{REFERÊNCIAS}

APPADURAI, A. Dimensões culturais da globalização. Lisboa: Teorema, 2004.

BHABHA, H. O local da cultura. $5^{\text {a }}$ reimpressão. Belo Horizonte: Ed. UFMG, 2010.

BARREIROS, D. R. A.; FRANGELLA, R. de C. P. Um novo olhar sobre o sentido de política nos estudos curriculares. Roteiro, Joaçaba, v. 35, n. 2, p. 231-250, jul./dez. 2010.

BURITY, J. Teoria do discurso e educação: reconstruindo o vínculo entre cultura e política. Revista Teias, v. 11, n. 22, p. 7-29, maio/ago. 2010.

CANCLINI, N. G. Culturas híbridas: estratégias para entrar e sair da modernidade. 4. ed. 4ª reimpressão. São Paulo: Edusp, 2008.

DERRIDA, J. Posições. Belo Horizonte: Autêntica, 2001. 
LOPES, A.; MACEDO, E. F. Teorias do currículo. São Paulo: Cortez, 2011.

MACEDO, E. Currículo e diferença. Convergências e tensões no campo da formação e do trabalho docente: currículo, XVENDIPE, 2010. (Mimeo.).

PRETTO, N. de L. Mídia, currículo e o negócio da educação. Currículo, cotidiano e tecnologias. Araraquara, SP: Junqueira \& Marin, 2006.

TURA, M. de L. R. Conhecimentos escolares e circularidades entre culturas. Currículo: debates contemporâneos. Rio de Janeiro: Cortez, 2002.

Roberta Sales Lacê Rosário é doutoranda do Programa de Pós-Graduação em Educação - ProPEd. Participante do Grupo de Pesquisa Currículo, Formação e Educação em Direitos Humanos - GECEDH e do Grupo de Pesquisa Formação em Diálogo: Narrativa de Professoras, Currículo e Culturas - GPFORMADI. Tutora a distância do Consórcio Cecierj/Cederj.

E-mail: robertarose1@yahoo.com.br

Bonnie Axer é doutoranda do Programa de Pós-Graduação em Educação - ProPEd. Participante do Grupo de Pesquisa Currículo: sujeitos, conhecimento e cultura e do Grupo de Pesquisa Currículo, Formação e Educação em Direitos Humanos - GECEDH. Professora substituta do Instituto de Aplicação Fernando Rodrigues da Silveira - CAp-UERJ. Tutora a distância do Consórcio Cecierj/Cederj.

E-mail: bonnieaxer@smail.com 